\title{
Landscape-scale controls on the spatial distribution of caesium- 137: a study based on an airborne geophysical survey across Northern Ireland
}

B. G. Rawlins ${ }^{1 *}$, C. Scheib ${ }^{1}$, D. Beamish ${ }^{1}$, R. Webster ${ }^{2}$, A. N. Tyler ${ }^{3}$ and M. E. Young ${ }^{4}$

${ }^{1}$ British Geological Survey, Keyworth, Nottingham NG12 5GG, UK

${ }^{2}$ Rothamsted Research, Harpenden, Hertfordshire AL5 2JQ, UK

${ }^{3}$ School of Biological and Environmental Sciences University of Stirling, Stirling FK9 4LA, Scotland UK.

${ }^{4}$ Geological Survey of Northern Ireland, Stranmillis Court, Malone Lower, Belfast BT9 5BF, UK

${ }^{*}$ Correspondence to: B. G. Rawlins, British Geological Survey, Keyworth, Nottingham $N G 125 G G, U K$.

E-mail: bgr@bgs.ac.uk 
ABSTRACT: The spatial distribution of ${ }^{137} \mathrm{Cs}$ across the landscape and the processes controlling its redistribution are of interest because (i) ${ }^{137} \mathrm{Cs}$ has been widely used to quantify the movement of soil and sediments and (ii) substantial fallout of ${ }^{137} \mathrm{Cs}$ after the Chernobyl accident has led to contamination of foodstuffs in some places. A highresolution airborne geophysical radiometric survey of Northern Ireland has provided an opportunity to study the distribution and possible redistribution of ${ }^{137} \mathrm{Cs}$.

The ${ }^{137}$ Cs activity (recorded at 1.2 million points) is distributed in a series of bands oriented approximately $160^{\circ}$ and $115^{\circ}$ clockwise from north. Geostatistical analysis of the data shows a strong, short-range structure (correlation ranges between 0.6 and $8 \mathrm{~km})$ in ${ }^{137} \mathrm{Cs}$ activity across the vast majority of the region; the spatial distribution shows association with a published, coarse-scale depositional pattern of ${ }^{137} \mathrm{Cs}$ from Chernobyl. Two indices of land form derived from a digital elevation model, namely compound topographic index and the length-slope factor of the Revised Universal Soil Loss Equation, account for only $3 \%$ of the variance in ${ }^{137} \mathrm{Cs}$ activity. In contrast, soil type and land cover in combination (including their interaction) account for $20 \%$ of the variance. In areas that received moderate fallout from Chernobyl, soil type alone accounts for a substantial proportion of the spatially correlated ${ }^{137} \mathrm{Cs}$ activity. We attribute this to each soil type's having a fairly uniform radiocaesium interception potential that differs from those of other soil types and that this potential controls the vertical migration of ${ }^{137} \mathrm{Cs}$. Over the granitic Mourne Mountains there is a strong spatial cross-correlation between ${ }^{137} \mathrm{Cs}$ activity and airborne estimates of soil potassium, suggesting that the latter provides a measure of the soil's radiocaesium interception potential; this is probably dominated by the quantity of the mineral illite.

KEYWORDS: caesium-137; soil; Northern Ireland; Chernobyl; geostatistics; wet deposition. 


\section{Introduction}

In northern Europe the soil contains caesium-137 $\left({ }^{137} \mathrm{Cs}\right)$ primarily from two sources: caesium released from the testing of atomic weapons largely between 1952 and 1962 (Carter and Moghissi, 1977) and fallout following the nuclear accident at Chernobyl on 26 April 1986 (ApSimon et al., 1989). The range of cumulative ground deposition of ${ }^{137} \mathrm{Cs}$ from atmospheric nuclear weapons testing between 1945 and 1985 over the northern hemisphere has been estimated to range from 0 to $9.38 \mathrm{kBq} \mathrm{m}^{-2}$ (Wright et al., 1999; decay corrected to 1985). In some regions deposition from Chernobyl far outweighs that from atmospheric weapons testing; Golosov (2002) cites moderate activities of ${ }^{137} \mathrm{Cs}$ deposition across northern Europe from the Chernobyl accident of up to $40 \mathrm{kBq} \mathrm{m}{ }^{-2}$.

The spatial distribution of ${ }^{137} \mathrm{Cs}$ is of much interest because it can tell us where gamma radiation might present a significant hazard through consumption of contaminated food. The spatial pattern of ${ }^{137} \mathrm{Cs}$ many years after deposition can also tell us about redistribution of the radionuclide as a result of soil erosion, differential migration through the soil — or its complement, differential retention in the soil.

There have been few published reports of the detailed spatial distribution of ${ }^{137} \mathrm{Cs}$ from Chernobyl over large areas (De Cort et al., 1998). Regional and national sets of data include those over central Russia (Izrael, 1993) and Austria (Bossew et al., 2001), both showing the widespread fallout from Chernobyl superimposed on that from the earlier weapons testing.

More recently, in 2005 and 2006, an airborne geophysical survey of the whole of Northern Ireland provided high-resolution estimates of ${ }^{137} \mathrm{Cs}$ for the $13500 \mathrm{~km}^{2}$ of the region. Approximately 20 years after the Chernobyl accident, this unique set of data provides a 'snapshot' representing the original fallout from Chernobyl superimposed on the background activity of radiocaesium from weapons testing, plus the effects of subsequent redistribution. This information can aid our understanding of the soil properties and processes controlling the retention and redistribution of ${ }^{137} \mathrm{Cs}$ over the land. 
It might also be possible to identify covariates that control the retention or migration of ${ }^{137} \mathrm{Cs}$ in the soil and so improve our understanding of the processes determining the redistribution of ${ }^{137} \mathrm{Cs}$ across the landscape.

We need to consider three main factors when we try to understand the presentday spatial distribution of ${ }^{137}$ Cs over northern Europe. First, as van Berghe and Gulink (1987) have shown, the deposition of ${ }^{137}$ Cs from atmospheric weapons testing is proportional to the amount of precipitation. Deposition of ${ }^{137} \mathrm{Cs}$ is dominated by wet deposition, and it is likely to have been fairly uniform at any one place as a result of the longer-term averaging effects of annual rainfall. Second, the superimposed pattern of deposition from Chernobyl would have been determined largely by the pattern of rainfall in the few days following the accident. Unfortunately, the rainfall at the time was measured at too few sites to establish a pattern that might have accounted for variation in the associated activities of ${ }^{137} \mathrm{Cs}$ at the local scale. Ground-based observations around the Sellafield nuclear plant in northern England showed that there was considerable local variation in the deposition of ${ }^{137} \mathrm{Cs}$ (Jackson et al., 1987). Third, a set of inter-related landscape features, including soil type, local geomorphology and land use control the interception, retention or migration of the deposited caesium, either vertically through the soil or laterally across the landscape.

Perhaps the most important soil property is the soil's radiocaesium interception potential (frequently abbreviated to RIP); this depends largely on the quantity and type of clay minerals (Sweek et al., 1990). Gil-García et al. (2009) compiled data on the distribution coefficients for the adsorption of radiocaesium determined in both the field and the laboratory, and showed that geometric mean partition coefficients (in litres per $\mathrm{kg}$ ) increased in the following order according to soil type (larger values represent greater adsorption): organic (270), sand (530), loam (3500) and clay (5500). So variation in the clay content of the soil, and hence its adsorption capacity, is likely to have led to differences in vertical migration of ${ }^{137} \mathrm{Cs}$ through the soil and consequently to differences in the activity of the radionuclide observed in our study region, Northern 
Ireland. According to Kirchner and Baumgartner (1992), ${ }^{137}$ Cs from Chernobyl is likely to have reached sorption equilibrium with the soil within 3 years because of the small hydration energy of the $\mathrm{Cs}^{+}$ion. In soils with large quantities of organic matter and few micaceous specific sorption sites, radiocaesium seems likely to be held mainly on ion exchange sites from which it is readily and reversibly exchangeable and available to plants. This has significance for Northern Ireland where approximately $14.7 \%$ of the total area is covered by peat (Cruickshank, 1997).

Land use influences the magnitude of wet deposition reaching the soil through interception by vegetation (Kinnersley et al., 1997). On agricultural land tillage exposes bare soil, which is then at risk to erosion and redistribution of any radiocaesium it contains. The effect of redistribution on ${ }^{137} \mathrm{Cs}$ can be substantially greater in some environments than that from differential adsorption, and it is the basis for the estimation of soil erosion in which the radionuclide is used as a tracer (Zapata, 2002). Land form also affects the transport of radiocaesium; Tyler and Heal (2000) showed that for organic upland soil, the compound topographic index (the CTI) accounted for a large proportion of the spatial variation in ${ }^{137} \mathrm{Cs}$ in a small upland catchment.

Our preliminary analysis of the spatial distribution of ${ }^{137} \mathrm{Cs}$ from the airborne survey of Northern Ireland suggested that much of the variation is of short range (between $<0.6$ and $8 \mathrm{~km}$ ). Other studies have also suggested that deposition of radiocaesium can vary substantially over short distances. For example, Albers et al. (1998) published the results of surveys of two 100-m transects in alpine pastures along which there was much variation in radiocaesium activity. Data compiled from observations of activities of ${ }^{137} \mathrm{Cs}$ in the soil at 750 sample sites in Cumbria in northern England between 1986 and 1999 showed that $75 \%$ of the spatial variation was unresolved at distances less than $350 \mathrm{~m}$ (Wright et al., 2002). Also, the initial pattern of radiocaesium deposition was identified as a factor in its short-range variation across a small catchment in Slovakia (van der Perk et al., 2002).

The current spatial pattern of ${ }^{137} \mathrm{Cs}$ has thus been determined by variation in 
(i) the fallout, (ii) the retention in the soil by adsorption and (iii) by redistribution over the land surface by erosion. Analyses of rainfall patterns over the United Kingdom soon after the Chernobyl accident suggested that quantities of ${ }^{137} \mathrm{Cs}$ similar to those recorded in northern England were deposited over Northern Ireland (Clark and Smith, 1988). In a more detailed report, the same authors (Smith and Clark, 1989) stated that radar data - which can be used to estimate patterns and intensities of rainfall accurately - were not available for Northern Ireland in 1986. As there were no radar data, Smith and Clark used measurements from 181 rain gauges and the timing and movement of the Chernobyl plume to estimate the amounts of rain that fell over the region having intercepted it (Figure 1).

Initially the amount of ${ }^{137} \mathrm{Cs}$ from Chernobyl would have been independent of variation in soil properties, except insofar as the soil is related to altitude and rainfall; typically the higher the land and the more rain received, the greater would have been the deposition of ${ }^{137} \mathrm{Cs}$. The soil map shows, however, that there is a wide variety of soil types in Northern Ireland, and we know that soil properties control to a large degree the retention or loss of caesium. We therefore expect the spatial distribution of ${ }^{137} \mathrm{Cs}$ to be related to the soil pattern evident on the soil map. We might also expect the spatial distribution of ${ }^{137} \mathrm{Cs}$ to reflect areas of soil accumulation and loss resulting from erosion. One can investigate this by calculating the spatial variation in topographic indices (e.g. slope angle and length or flow accumulation) derived from digital elevation models and making statistical comparisons with the patterns of ${ }^{137} \mathrm{Cs}$.

The airborne survey geophysical survey of Northern Ireland, in which the activities of ${ }^{137} \mathrm{Cs}$ and three naturally occuring radionuclides were determined across the entire landscape, provides an opportunity to explore the relative importance of the factors which have contributed to its spatial distribution. We analysed these data geostatistically both over the region as a whole and locally. We assess the degree to which the depositional pattern of ${ }^{137} \mathrm{Cs}$ from Chernobyl as estimated by Clark and Smith (1988) can be identified from the airborne survey. We assess the relative importance 
of five landscape factors (land cover, soil properties, erosive potential and topographic accumulation) in controlling the retention or migration of ${ }^{137} \mathrm{Cs}$ across all of Northern Ireland and where fallout was greatest. We then focus on the Mourne Mountains where the distribution of ${ }^{137} \mathrm{Cs}$ has a particularly short-range pattern. We show that potassium in the soil, also estimated from the airborne survey, is coregionalized with ${ }^{137} \mathrm{Cs}$ for this smaller region. We also discuss the wider implications of our findings.

\section{Background to the study area}

\section{Soils, land-use and topography}

The soils of Northern Ireland have been described by Cruickshank (1997). They comprise poorly-drained gley soils (54\%), peat and rankers (24\%) and freely drained soils $(16 \%)$ - see Figure 2. Digital versions of soil maps at 1:50 000 were available for all of Northern Ireland with 19 unique codes, one for each major soil group (Cruickshank, 1997). Grassland is the dominant land use in Northern Ireland (72\%), with a smaller proportion of rough grazing (18\%); only $6 \%$ of the land is cultivated, $1 \%$ is woodland and the other $3 \%$ consists of a range of other land use types. To help assess the degree of association between land use and the distribution of ${ }^{137} \mathrm{Cs}$ we extracted digital polygons of land cover from the CORINE data of 2000 (Nunes de Lima, 2005) for Northern Ireland (1:100 000 scale). Thirty five types of land cover were recorded. A brief analysis of ten, historical 1:63 600 scale maps (Government of Northern Ireland, 1947-1951) published following the land utilization survey of Northern Ireland (1938-1939) shows the only significant change is a decline in the proportion of arable land since the second world war; at that time more land area was cultivated. The Land Cover Map of 2000 shows that most of this arable land has since been converted to pasture; this change is likely to have been before the accident at Chernobyl. The impact of this change on the migration of ${ }^{137} \mathrm{Cs}$ deposited from Chernobyl is likely to have been small.

Northern Ireland has a varied topography, with $75 \%$ of the land area below $150 \mathrm{~m}$ elevation-mostly around Lough Neagh - and only $6 \%$ above $300 \mathrm{~m}$. There are four main upland areas; the Tertiary basalt plateau, the Sperrin Mountains, the granitic 
Mourne Mountains, and finally the plateau area to the west of Lough Erne (Figure 3). We obtained a digital elevation model covering all of Northern Ireland, accurate to $1 \mathrm{~m}$ on a 50-m grid (photogrammetrically derived by the Ordnance Survey of Northern Ireland $\left.{ }^{\mathrm{R}}\right)$.

${ }^{137}$ Cs deposition

McAulay and Moran (1989) assessed the fallout of ${ }^{137}$ Cs over the Republic of Ireland and Northern Ireland both from Chernobyl and weapons testing. They measured the activities of ${ }^{137} \mathrm{Cs}$ and ${ }^{134} \mathrm{Cs}$ at 110 sites in August 1986 and calculated the residual component of ${ }^{137} \mathrm{Cs}$ from weapon tests after subtracting the ${ }^{137} \mathrm{Cs}$ from Chernobyl, which they calculated from the known ratio of the two isotopes released from the accident. Using the standard radioactive decay equation, and the half-life of ${ }^{137} \mathrm{Cs}$ (30.17 years), we calculated from their results the activity of ${ }^{137} \mathrm{Cs}$ from weapon tests remaining when the airborne geophysical survey of Northern Ireland was flown. This gave a ${ }^{137} \mathrm{Cs}$ mean of $0.5 \mathrm{kBq} \mathrm{m}{ }^{-2}$ to a depth of $30 \mathrm{~cm}$ from weapon tests, though the activity ranged up to $3.4 \mathrm{kBq} \mathrm{m}^{-2}$ on some shallow upland soils, which McAulay and Moran attributed to the larger, local average annual rainfall. With respect to the deposition of ${ }^{137}$ Cs from Chernobyl, Smith and Clark (1989) stated , '. . . the convective rainfall and deposition shows a banded structure . . . much of the rainfall from deep convective storms . . . with narrow footprints elongated alongwind, with similar footprints of activity-deposition'. They produced a choropleth map based on estimated rainfall that intercepted the radioactive plume for the period 2-4 of May 1986, following the Chernobyl accident (see Figure 1). It shows that the land receiving the most rain $\left(>10 \mathrm{~mm}\right.$ ) occurred in two bands (oriented approximately $115^{\circ}$ clockwise from north) in the north and central-south of the region. Although some of the uplands receive more rain in total than lowland areas, the broad patterns over this two day period are not closely related to altitude.

\section{Methods}




\section{Airborne geophysical survey}

The Tellus airborne geophysical survey of Northern Ireland, flown in 2005 and 2006, comprised more than $82000 \mathrm{~km}$ of flight lines. High-resolution radiometric data were acquired with an Exploranium GR820 256-channel NaI(Tl) gamma spectrometer system of four downward (32 litres) and one upward-looking (8 litres) crystal sets. Data from the sensor were recorded every second corresponding to approximately 60-m intervals in the direction of flight. Survey lines were spaced $200 \mathrm{~m}$ apart with flight lines oriented at $345^{\circ}$ and $165^{\circ}$. Perpendicular tie-lines $2000 \mathrm{~m}$ apart were flown in the early stages of the survey, covering only the western portion of the region. The aircraft flew $56 \mathrm{~m}$ above ground in rural areas, but higher $(244 \mathrm{~m})$ above elevated structures and urban areas. The ground area or 'footprint', from which most of the radiation recorded comes, has the form of an ellipse elongated in the direction of flight. For example, at $56 \mathrm{~m}$ above the ground $75 \%$ of the measured radiation comes from an ellipse with a long diameter of $220 \mathrm{~m}$ in the flight direction and perpendicular diameter of $150 \mathrm{~m}$ (Pitkin and Duval, 1980). A complete description of the airborne geophysical systems deployed and the processing methods used is given by Hautaniemi et al. (2005). Procedures for processing the airborne radiometric data were based on those described in the reference manuals of the International Atomic Energy Authority (IAEA, 1991) and the Australian Geological Survey Organisation (AGSO; Grasty and Minty, 1995). The processing included corrections for aircraft and cosmic background radiation, altitude of the aircraft and spectral interactions. Gamma radiation measured by the airborne system comes from a thin surface layer of about $30 \mathrm{~cm}$ in rock, rather more in less dense unconsolidated material such as mineral soil, to a maximum of a few metres in dry peat.

The corrected count rates were used to estimate the concentration of three natural radioelements within the conventional energy ranges: $\mathrm{K}(1.37-1.57 \mathrm{MeV})$, equivalent $\mathrm{U}$ (eU, derived from ${ }^{214} \mathrm{Bi}, 1.66-1.86 \mathrm{MeV}$ ) and equivalent Th (eTh, derived from ${ }^{208} \mathrm{Tl}$, 2.41-2.81 MeV) (IAEA, 1991). In addition, the activities of the anthropogenic radionu- 
clide ${ }^{137}$ Cs were determined from the same spectra. The survey yielded ca 1.2 million values for $\mathrm{K}(\%)$, eTh $\left(\mathrm{mg} \mathrm{kg}^{-1}\right)$ and $\mathrm{eU}\left(\mathrm{mg} \mathrm{kg}^{-1}\right)$ and activities of ${ }^{137} \mathrm{Cs}\left(\mathrm{kBq} \mathrm{m}^{-2}\right.$. Estimated activities of ${ }^{137} \mathrm{Cs}$ were based on a full spectrum, least-squares fitting procedure (Minty, 1998) in the Praga ${ }^{T M}$ extension to the Oasis montaj ${ }^{T M}$ software package (Geosoft Inc). Calibration was carried out to take account of the possible interference caused by the close proximity of the $609 \mathrm{KeV}{ }^{214} \mathrm{Bi}$ energy line to ${ }^{137} \mathrm{Cs}$ (662 KeV); exploratory data analysis suggested that this interference may introduce a small amount of bias.

A comparison between ground-based and airborne measurements of the activities of ${ }^{137} \mathrm{Cs}$ was undertaken at a series of ground reference locations to ensure the latter were of reasonable accuracy and to assess the degree and variation in the extent of vertical migration of ${ }^{137} \mathrm{Cs}$. Estimation of the activities of ${ }^{137} \mathrm{Cs}$ from both groundbased and airborne detectors rely on assumptions concerning the depth distribution of ${ }^{137} \mathrm{Cs}$ - the assumption of exponential decrease with depth soon after deposition becomes less accurate over time as ${ }^{137} \mathrm{Cs}$ migrates vertically through the soil. The fluence rate of photons at the land surface from a gamma source is related to its vertical distribution in the soil which is incorporated in calculations of integrated activity per unit area, $A_{a}\left(\mathrm{~Bq}^{-2}\right)$ by the mean mass depth $(\beta)$ :

$$
A_{a}=\beta A_{m, 0}
$$

where $A_{m, 0}$ is activity per unit mass at the surface of the soil $\left(\mathrm{Bq} \mathrm{g}^{-1}\right)$.

Along four transects (total length $40 \mathrm{~km}$ ) with varying soil properties, 80 separate in situ gamma spectrometry measurements were undertaken using a Ge detector. At one site along each transect, five soil cores (0 to $40 \mathrm{~cm}$ depth) were collected for laboratory-based measurement of the activities of ${ }^{137} \mathrm{Cs}$ at 5 -cm incremental depths.

Distributions of activities of ${ }^{137} \mathrm{Cs}$ down the soil cores were varied; at one site there was an exponential decline in activity of ${ }^{137} \mathrm{Cs}$ with depth, whilst at others there were subsurface maxima. The ground-based measurements were processed assuming a mean mass depth $(\beta)$ of $10 \mathrm{~g} \mathrm{~cm}^{-2}$. Following the guidance for the processing airborne 
survey data (IAEA, 1993), we assumed ${ }^{137}$ Cs declined exponentially with depth; a mean mass depth $(\beta)$ value of $1 \mathrm{~g} \mathrm{~cm}^{-2}$ was applied to all the airborne survey data, Equation ( ??). The influence of depth distribution is smaller for airborne survey because at altitudes of $60 \mathrm{~m}$ the solid angle is much smaller than at $1 \mathrm{~m}$ - a typical measurement height for ground-based detectors (ICRU, 1994; Tyler, 2007).

A comparison between the ground-based and airborne measurements for all reference locations is shown in Figure 4. Despite the large differences between the scales of measurements for these two methods, there is a strong linear relationship between the estimated activities of ${ }^{137} \mathrm{Cs}$ for the reference sites (linear correlation coefficient $r=0.79)$. The airborne measurements of the activities of ${ }^{137} \mathrm{Cs}$ are generally smaller than the ground-based measurements. These differences may be accounted for by the smaller mean mass depth $(\beta)$ used in the former. A larger mean mass depth indicates greater attenuation of the gamma-ray signal by the overlying soil, resulting in larger estimates of the activities of ${ }^{137} \mathrm{Cs}$.

At the scale of airborne survey it is not possible to adjust $\beta$ during data processing to account for the short-range variation in depth distributions of the activities of ${ }^{137} \mathrm{Cs}$. Therefore, our airborne survey provides estimates of the activities of ${ }^{137} \mathrm{Cs}$ based on their spatial variation and an assumption concerning vertical migration. Selecting a larger, constant mean mass depth $(\beta)$ would alter the magnitude of the estimated activities of ${ }^{137} \mathrm{Cs}$, but not the differences between them. However, the proportion of variation in estimated ${ }^{137} \mathrm{Cs}$ activities attributable to the different soil and land use types may be overestimated by assuming a constant mean mass depth over all sites. This is because at those sites where ${ }^{137} \mathrm{Cs}$ subsurface maxima occur deeper than a few centimetres attenuation of the gamma-ray signal by overlying soil will be greater than that assumed by our model, leading to an underestimate of the activities of ${ }^{137} \mathrm{Cs}$. This will exaggerate the differences in the estimates of ${ }^{137} \mathrm{Cs}$ activities at these sites when compared with those with surface maxima $(1-2 \mathrm{~cm})$ of ${ }^{137} \mathrm{Cs}$.

\section{Landscape factors}


We calculated the length-slope (LS) factor in the Revised Universal Soil Loss Equation (RUSLE) as a standard, dimensionless estimate of the amount of soil likely to be lost by erosion. Its formula is

$$
\mathrm{LS}=\left(\frac{\lambda}{22.3}\right)^{m} \times S
$$

where $\lambda$ is the flow path length (in metres) and $m$ is the ratio of rill-to-interill erosion. The quantity $S$ depends on the slope, $\beta$, as follows.

$$
\begin{aligned}
& S=10.8 \sin \beta+0.03 \quad \text { for } \tan \beta<0.09 \\
& S=16.8 \sin \beta-0.5 \quad \text { for } \tan \beta \geq 0.09 .
\end{aligned}
$$

We made the calculations for a 50-m grid using the digital elevation model (DEM) and an ArcInfo ${ }^{\mathrm{TM}}$ script, as described by Van Remortel et al. (2001). We used the DEM to calculate compound topographic index (CTI as defined by Quinn et al., 1991) on the 50-m grid using the D-infinity algorithm of Tarboton (1997):

$$
\mathrm{CTI}=\ln \left(\frac{A}{\tan \beta}\right)
$$

where $A$ is the specific catchment area and $\beta$ is the slope angle, here locally. We used a GIS spatial join procedure to associate each airborne radiometric survey point with a digital soil polygon and its associated soil feature code, a CORINE code for class of land cover, a rainfall polygon (Figure 1), a length-slope factor value, a CTI value and its altitude (metres above mean sea level). To assess the importance of five of the

landscape factors (CTI, length-slope, soil type, altitude and land cover) on the spatial distribution of ${ }^{137} \mathrm{Cs}$ across all of Northern Ireland, we selected a random subset of 50000 of the survey points.

\section{Statistical analysis}

Table 1 summarizes the statistics of activities of ${ }^{137} \mathrm{Cs}$ for the whole region and for each of the rainfall classes in Figure 1. Histograms of the data showed that for each rainfall class and for the entire survey area the distributions were approximately normal, and 
this inference accords with the skewness coefficients between -0.14 and 0.15 listed in Table 1. We interpolated values from all of the data on to a fine grid and created a continuous colour map of activities of ${ }^{137} \mathrm{Cs}$ for the region (Figure 3).

We also wished to explore the spatial variation for the individual rainfall classes shown on this map. To assess the spatial structure of activities of ${ }^{137} \mathrm{Cs}$ for each rainfall class we first examined the data for trend across the entire survey region and found none. We then computed variograms from the data using Matheron's standard estimator to a maximum lag of $20 \mathrm{~km}$ :

$$
\widehat{\gamma}_{u v}(\mathbf{h})=\frac{1}{2 m(\mathbf{h})} \sum_{j=1}^{m(\mathbf{h})}\left\{z_{u}\left(\mathbf{x}_{j}\right)-z_{u}\left(\mathbf{x}_{j}+\mathbf{h}\right)\right\}\left\{z_{v}\left(\mathbf{x}_{j}\right)-z_{v}\left(\mathbf{x}_{j}+\mathbf{h}\right)\right\} .
$$

Here $z_{u}\left(\mathbf{x}_{j}\right)$ and $z_{u}\left(\mathbf{x}_{j}+\mathbf{h}\right)$ and $z_{v}\left(\mathbf{x}_{j}\right)$ and $z_{v}\left(\mathbf{x}_{j}+\mathbf{h}\right)$ are the observed values of any two variables $u$ and $v$ at positions $\mathbf{x}_{j}$ and $\mathbf{x}_{j}+\mathbf{h}$ separated by the lag vector $\mathbf{h}$, and $m(\mathbf{h})$ is the number of paired comparisons at that lag. If $u=v$ then we obtain the auto-variogram for variable $u$; if not then we obtain the cross-variogram for $u$ and $v$. There was no evidence for anisotropy, so we treated the lag as a scalar in distance only, i.e. $h=|\mathbf{h}|$, and fitted isotropic functions to model the experimental auto-variograms by weighted least-squares.

The next stage of our analysis was to determine the separate and combined effects of two factors (land cover and soil type) on activities of ${ }^{137} \mathrm{Cs}$. For this we first did a one-way analysis of variance (ANOVA) on each factor independently. We then did a two-factor analysis, but as the classes contain disparate numbers of observations we had to use residual maximum likelihood (REML, Patterson and Thompson, 1971) for the purpose. This involved adding the factors sequentially, and because the two factors are confounded the estimates of their effects depend on the order in which they are added in the model. We therefore did two analyses, one with land cover entered first and the other with soil type added first. The interaction is unaffected by the order of entry into the model. We selected the $40 \%$ of survey points with length-slope values greater than the minimum; these values were positively skewed (skewness coefficient=2.22) and so we took natural logarithms to stabilize the variances (skewness $=0.01$ ). The 
distribution of CTI values was less (but still positively) skewed, so we transformed CTI to their square roots. Finally, we calculated the multiple linear regression of ${ }^{137} \mathrm{Cs}$ on the transformed LS and CTI by least squares.

In addition to our analyses of activities of ${ }^{137} \mathrm{Cs}$ covering the entire region described above, we undertook two sets of more local analyses. The first concerned the area estimated to have received between 15 and $20 \mathrm{~mm}$ of rain from during the three days of 2, 3 and 4 May 1986 following the Chernobyl accident (1840 km²; Figure 1). We selected this region because it had the largest median activities of ${ }^{137} \mathrm{Cs}$ (Table 1); the signal-to-noise ratio is greater here than elsewhere, so the effect of measurement error on comparisons between these data is minimal. We examined in greater detail how the landscape factors relate to the spatial distribution of activities of ${ }^{137} \mathrm{Cs}$. We expanded the regression model above to include the soil type, land cover and altitude in addition to LS and CTI. We then computed variograms of the residuals from the models to a maximum lag of $20 \mathrm{~km}$. To these we fitted optimum authorized models as above using GenStat, and the results are shown in Figure 5.

In the event we found that double exponential models with nugget components fitted best in most instances. Their formula is

$$
\begin{aligned}
\gamma(h) & =c_{0}+c_{1}\left\{\exp -\left(\frac{h}{a_{1}}\right)\right\}+c_{2}\left\{\exp -\left(\frac{h}{a_{2}}\right)\right\} \quad \text { for } h>0 \\
& =0 \text { for } h=0
\end{aligned}
$$

in which $c_{0}$ is the nugget variance, $c_{1}$ and $c_{2}$ are the sill variances of the short-range and longer-range components respectively, and $a_{1}$ and $a_{2}$ are the corresponding distance parameters and equal approximately to $0.33 \times$ the effective ranges of those components. The distance parameter $a_{1}$ varied between 0.2 and $3 \mathrm{~km}$, and $a_{2}$ from 3 to $55 \mathrm{~km}$.

The second set of local analyses were of those observations over the Mourne Mountains only; note that activities of ${ }^{137} \mathrm{Cs}$ exhibit a larger proportion of short-range variation in this part of the region (see Figure 3). Assuming the initial deposition was not entirely responsible for this local variation, we considered that further analysis of the distribution of ${ }^{137} \mathrm{Cs}$ might help us to understand the processes controlling its mi- 
gration better. The Mourne Mountains are composed entirely of granite which weathers to clay, including the mineral illite (McAlister et al., 1997) which could account for much of the variation in the RIP of the soil. For them we computed auto-variograms of activities of ${ }^{137} \mathrm{Cs}$ and estimates of $\mathrm{K}(\%)$ content and their cross-variogram to a lag of $4 \mathrm{~km}$ at intervals of $100 \mathrm{~m}$. To these we fitted an isotropic linear model of coregionalization:

$$
\gamma_{u v}(h)=\sum_{k=1}^{K} b_{u v}^{k} g_{k}(h),
$$

in which the $g_{k}, k=1,2, \ldots, K$, are basic variogram functions with a priori variances of 1 and specific distance parameters, and the coefficients $b_{u v}^{k}$ are the sill variances of second-order stationary processes.

From the fitted models we also calculated the structural correlation coefficients to aid our understanding of the changes in correlation with changes in spatial scale. These coefficients, $\rho^{k}$, are analogous to the familiar Pearson correlation coefficient, but each is specific to the component of variation represented by the basic variogram function, $g_{k}(h)$, and so is specific to a particular spatial scale of variation (Goovaerts and Webster, 1994). They are estimated from the sill variances by

$$
\widehat{\rho}_{u v}^{k}=\frac{b_{u v}^{k}}{\sqrt{b_{u u}^{k} b_{v v}^{k}}} .
$$

\section{Results and interpretation}

\section{Rainfall and ${ }^{137}$ Cs distribution}

The median activities of ${ }^{137} \mathrm{Cs}$ increase with increasing estimates of rainfall intercepted by the plume (Table 1), although the two largest classes have similar values. However,

Figure 3, the map of activities of ${ }^{137} \mathrm{Cs}$, shows much greater complexity than that of the rainfall polygons in Figure 1. The former displays three sets of linear bands of greater $\left(>3.5 \mathrm{kBq} \mathrm{m}^{-2}\right){ }^{137} \mathrm{Cs}$ activities oriented approximately $160^{\circ}$ clockwise from north and another series of smaller bands oriented approximately $115^{\circ}$ clockwise from north, to the south and west of Lough Neagh. The auto-variograms for the individual 
classes of rainfall revealed the largest proportion of spatially correlated variance where estimated intercepted rainfall was greatest after the Chernobyl accident (Figure 6). As above, the auto-variogram models comprise three components: a nugget plus two nested exponential components (Table 2). In this study we believe the nugget component of approximately $0.55\left(\mathrm{kBq} \mathrm{m}^{-2}\right)^{2}$ to be dominated by measurement error; there is almost no nugget in the cross-variogram of ${ }^{137} \mathrm{Cs}$ and potassium in the Mourne Mountains (see below and Figure 7 and Table 5).

For each auto-variogram, the first exponential component accounts for a large proportion of the spatially correlated variance at distances $<3 \mathrm{~km}$; this component is especially marked in the 10-15 mm rainfall class (Figure 5). We attribute this structure to the combination of two factors; the depositional pattern of fallout and the factors controlling the subsequent migration of the ${ }^{137} \mathrm{Cs}$, but we cannot separate their relative importance.

\section{Landscape factors}

In combination, the CTI and length-slope factors accounted for only $3 \%$ of the variance in activities of ${ }^{137} \mathrm{Cs}$ (coefficient of determination $R^{2}=0.03$ ) across all of Northern Ireland. This suggests that transport of ${ }^{137} \mathrm{Cs}$ by erosion-at the national scale - was not a major factor controlling its redistribution since deposition. This is probably because of the dominance of permanent grass, which virtually prevents erosion; the vertical redistribution of soil particles to which ${ }^{137} \mathrm{Cs}$ is adsorbed, predominates. Soil type and land cover class accounted for significant proportions of the variance: 14.9 and $15.7 \%$, respectively (calculated from the sum of squares for each factor as a proportion of the total sum of squares; Table 3). In combination (including their significant interaction) they accounted for $19.6 \%$ of the variance: the residual variance is 0.7880 out of the total of 0.9796 (Table 4). Note that because the factors are confounded the values in Table 4 depend strongly on the order in which they are entered in the model for the analysis.

Differences in the rates at which ${ }^{137}$ Cs moves from soil to plants (Gastberger 
et al., 2000), the fixation of radiocaesium in the biomass and cycling between living and dead parts of the vegetation can explain why land cover accounts for so much of the variation in activities of ${ }^{137} \mathrm{Cs}$. The substantial confounding effect between soil type and land cover occurs because particular ecosystems have developed - and land is managed - on certain soil types.

\section{Areas receiving 15-20 $\mathrm{mm}$ of plume-intercepted rainfall}

Of the four landscape factors, which might have determined the current patterns of activities of ${ }^{137} \mathrm{Cs}$, exploratory analysis suggested that both soil type and altitude could account for a significant proportion of the variation in activities of ${ }^{137} \mathrm{Cs}$ in the area that received 15-20 $\mathrm{mm}$ of rainfall. Figure 6 shows the variograms of the residuals when these two factors were used as predictors in linear regression models, and Table 2 lists the estimated parameters. Altitude accounts for a small proportion of the spatially correlated variance, whilst soil type accounts for a significantly larger proportion; $16 \%$ of the spatially correlated variance at both short $(3 \mathrm{~km})$ and longer distances $(20 \mathrm{~km})$. When both factors are considered together the spatial structure in the residuals is complex; at short distances $(<10 \mathrm{~km})$ less variance is accounted for than for soil type alone, but at longer distances $(>10 \mathrm{~km})$ there are independent effects which account for a greater proportion of the variance than each individually. This suggests that common soil properties, captured by the soil classes, determine the differential retention or vertical migration of ${ }^{137} \mathrm{Cs}$. The activities of ${ }^{137} \mathrm{Cs}$ for the various soil types (Figure 8), reveal some notable differences in their distributions.

Those soil types with finer textures (e.g. alluvium and many of the gleyed soils) tend to have greater median activities of ${ }^{137} \mathrm{Cs}$ than the overall median. The disturbed land and Brown Earths have smaller medians $\left(<2 \mathrm{kBq} \mathrm{m}^{-2}\right)$. The lack of cover and coarse soil texture favour leaching.

${ }^{137}$ Cs distribution on the Mourne Mountains

There were 5745 survey points on the Mourne Mountains, and, as above, we computed 
the auto-variograms of both ${ }^{137} \mathrm{Cs}$ and potassium and their cross-variogram and fitted to them a linear model of coregionalization. The results are displayed in Figure 7 with parameters listed in Table 5. The correlation range, approximately $1.2 \mathrm{~km}$, is substantially shorter than that for Northern Ireland as a whole (ca $10 \mathrm{~km})$ suggesting that the soil varies in a more intricate pattern there.

There is a fairly strong, joint spatial correlation between activities of ${ }^{137} \mathrm{Cs}$ and estimates of soil K (Figure 7c); the spatially structured correlation coefficient, Equation (??), is $r=0.69$. This suggests that the radiocaesium interception potential of the soil could be estimated from the K content, or, perhaps better, from the illite content; illite has been reported as both a major and minor mineralogical component of these soils (see McAlister et al., 1997). Caesium-137 is strongly adsorbed on frayed-edge sites of illite which are generated by weathering and possibly by the action of large hydrated cations such as $\mathrm{Ca}^{2+}$ and $\mathrm{Mg}^{2+}$ (Comans et al., 1991). Our observation that ${ }^{137} \mathrm{Cs}$ and $\mathrm{K}$ are jointly correlated for this area with a single, granitic parent material accords with results of studies by Waegeneers et al. (1999) who showed that the radiocaesium interception potential of soil depends on its geological origin.

\section{Discussion}

In estimating activities of ${ }^{137} \mathrm{Cs}$ in soil across Northern Ireland we assumed that their distribution with depth through the soil decreases exponentially; this was confirmed for some sites, but at others this was not the case (see Methods section). A recent paper by Jarvis et al. (2010) might explain why to some extent. Earthworms ingest soil to which ${ }^{137} \mathrm{Cs}$ is adsorbed and move it down the profile and so dilute ${ }^{137} \mathrm{Cs}$ near the surface. Where the assumption concerning exponential decrease does not apply, airborne measurement will underestimate activities of ${ }^{137} \mathrm{Cs}$. This is more likely to occur in organic and sandy soils types, which have smaller radiocaesium interception potentials, than in silt and clay-rich soils. This could exaggerate the differences in activities of ${ }^{137} \mathrm{Cs}$ between soil types that we reported from our analysis. Without many measurements of ${ }^{137} \mathrm{Cs}$ down the profile, however, we cannot quantify the magnitude 
of this effect.

Palsson et al. (2006) showed that one might be able to estimate the spatial distribution of ${ }^{137} \mathrm{Cs}$ fallout from weapons testing using long-term monitoring of ${ }^{137} \mathrm{Cs}$ deposition in combination with average annual precipitation data. They applied this method in Iceland. By subtracting global fallout from measurements of total activities of ${ }^{137} \mathrm{Cs}$ one might be able to estimate the separate component derived from Chernobyl. We did not attempt to do this for the ${ }^{137}$ Cs data for Northern Ireland for two reasons. First, like Palsson et al., we were concerned that the error in estimating average annual precipitation by interpolation from sparse rain gauges ( $c a 1$ per $72 \mathrm{~km}^{2}$ ) could lead to large errors in spatial estimates of global fallout. Estimates of annual precipitation might be improved by topographic data and precipitation modelling, but they were beyond the scope of this study. Second, the measurement error associated with estimated activities of ${ }^{137} \mathrm{Cs}$ from the airborne survey is too large to allow fine comparisons of this kind. If we assume that the spatial component of the nugget variance is negligible for ${ }^{137} \mathrm{Cs}$ — which is reasonable given that the nugget variance in our cross-variogram of $\mathrm{K}$ and activities of ${ }^{137} \mathrm{Cs}$ is negligible - then the nugget variance in the auto-variogram of the ${ }^{137} \mathrm{Cs}$ activity, approximately $0.55\left(\mathrm{kBq} \mathrm{m}^{-2}\right)^{2}$, provides an approximation to the measurement error. It would not be possible to separate this error from the error in estimation of global fallout.

Our geostatistical analysis of the airborne survey data showed that activities of ${ }^{137}$ Cs across Northern Ireland exhibits much variation over short distances, between $<0.6$ and $8 \mathrm{~km}$. When radio-caesium is used to quantify soil erosion on agricultural land, the methodology relies on the assumption that it was originally distributed fairly uniformly and that any subsequent variation calculated from ${ }^{137} \mathrm{Cs}$ inventories down individual slopes is due largely to redistribution by erosion (Walling and Quine, 1991). This assumption might be invalid for the large areas of pastoral land in Northern Ireland because of the short-range variation observed in the survey and because of the vertical translocation of the adsorbed ${ }^{137} \mathrm{Cs}$ by earthworms mentioned above. However, when 
we analysed the spatial structure of activities of ${ }^{137} \mathrm{Cs}$ for the relatively small area of arable land (mean activities of ${ }^{137} \mathrm{Cs}$ of $1.4 \mathrm{kBq} \mathrm{m}^{-2}$ ) we found no short-range structure similar to that observed for the region as a whole. This suggests that the arable land received little fallout from Chernobyl.

\section{Conclusions}

The main conclusions from our study are as follows.

1. The spatial distribution of activities of ${ }^{137} \mathrm{Cs}$ estimated for Northern Ireland from a high-resolution airborne geophysical survey in 2005 and 2006 has a pronounced short-range structure $(<0.6-8 \mathrm{~km})$ across the region, and a series of oriented bands with larger than average activities $\left(>3.5 \mathrm{kBq} \mathrm{m}^{-2}\right)$. The larger activities in these bands accord with the broad patterns of rainfall during the three days 2, 3 and 4 May 1986 following the nuclear accident at Chernobyl on 26 April of that year. However, the ${ }^{137} \mathrm{Cs}$ distribution from the survey — which includes a component of fallout from the testing of weapons - exhibits far greater spatial complexity than can be captured by the rainfall map of Smith and Clark (1989),

2. Two grid-based topographic, landscape indices (compound topographic index and the length-slope factor from RUSLE) which relate to water, and loss and accumulation of sediment, account for less than $3 \%$ of the spatial variation in the distribution of radio-caesium across all of Northern Ireland. This suggests that the dominant controls on the movement of ${ }^{137} \mathrm{Cs}$ at this regional scale are retention through adsorption followed by vertical migration, rather than lateral transport.

3. In combination, maps of land cover and soil type account for almost $20 \%$ of the spatial variation in the distribution of radiocaesium in the region. Part of the variation accounted for by these maps may be due to an artefact of the measurement process; spatial variation in the depth of migration of caesium-137 cannot be accounted for in airborne survey, but this will influences estimates 
of the activities of ${ }^{137} \mathrm{Cs}$. This highlights the importance of land use and soil type, respectively, for the biogeochemical cycling of ${ }^{137} \mathrm{Cs}$ and its retention, which control the rate of vertical migration of the nuclide.

4. Without estimates of ${ }^{137} \mathrm{Cs}$ at a fine-resolution at different times one cannot determine the relative importance of depositional pattern or landscape factors in accounting for the observed short-range spatial variation.

5. Over the Mourne Mountains there is a fairly strong, positive joint spatial correlation between activities of ${ }^{137} \mathrm{Cs}$ and $\mathrm{K}$ in the soil, both estimated from the airborne survey. This suggests that the radiocaesium interception potential of the soil is correlated with the soil's $\mathrm{K}$ content. It is likely to be due to the mineral illite which occurs in varying proportions in the soil there and weathered from the granitic parent material.

\section{Acknowledgements}

The Tellus project was funded by the Department of Enterprise, Trade and Investment and by the Building Sustainable Prosperity Scheme of the Rural Development Programme (Department of Agriculture and Rural Development of Northern Ireland). We acknowledge the huge survey effort undertaken by the Tellus and Joint AirborneGeoscience Capability (JAC) teams. We also thank Pavel Jurza for his assistance with the radiometric processing and Dave Jones for helpful comments in preparation of this paper. This paper is published with the permission of the Executive Director of the British Geological Survey (Natural Environment Research Council). Topographic

data based upon Ordnance Survey of Northern Ireland's ${ }^{\circledR}$ data are included with the permission of the Controller of Her Majesty's Stationery Office, CCrown copyright and database rights Licence Number DMOU205. Finally we thank the Agri-Food and Biosciences Institute (Belfast) for providing the soil maps of Northern Ireland under licence. 


\section{References}

Albers BP, Rackwitz R, Schimmack W, Bunzl K. 1998. Transect survey of radiocesium in soils and plants of two alpine pastures. Science of the Total Environment 216: $159-172$.

ApSimon HM, Wilson JJN, Simms KL. 1989. Analysis of the dispersal and deposition of radionuclides from Chernobyl across Europe. Proceedings of the Royal Society of London, Series A 425: 365-405.

Bossew P, Ditto M, Falkner T, Nenrich E. Kienzl K, Rappelsberger U. 2001. Contamination of Austrian soil with caesium-137. Journal of Environmental Radioactivity 55: $187-194$.

Carter MW, Moghissi AA. 1977. Three decades of nuclear testing. Health Physics 33: $55-71$.

Clark MJ, Smith FB. 1988. Wet and dry deposition of Chernobyl releases Nature, London 332: 245-249.

Comans RNJ, Haller M, de Preter P. 1991. Sorption of cesium on illite: Nonequilibrium behavior and reversibility. Geochimica et Cosmochimica Acta 55: $433-440$.

Cruickshank JG. 1997. Soil and Environment: Northern Ireland. Department of Agriculture for Northern Ireland and the Queen's University: Belfast.

De Cort M, Dubois G, Fridman SD, Germenchuk MG et al. 1998. Atlas of Caesium Deposition on Europe after the Chernobyl Accident. EUR Report 16733. EC Office for the Official Publications of the European Communities: Luxembourg.

Gastberger M, Steinhäusler F, Gerzabek MH, Lettner H, Hubmer A. 2000. Soil-toplant transfer of fallout caesium and strontium in Austrian lowland and Alpine pastures. Journal of Environmental Radioactivity 49: 217-233. 
Gil-García C, Rigol A, Vidal M. in press. New best estimates for radionuclide solidliquid distribution coefficients, part 1: radiostrontium and radiocaesium. Journal of Environmental Radioactivity 100: 697-703.

Golosov VN. 2002. Special consideration for areas affected by Chernobyl fallout. In Handbook for the Assessment of Soil Erosion and Sedimentation using Environmental Radionuclides, Zapata F, (ed). Kluwer Academic Publishers: Dordrecht; $165-183$

Goovaerts P, Webster R. 1994. Scale-dependent correlation between topsoil copper and cobalt concentrations in Scotland. European Journal of Soil Science 45: 79-95.

Government of Northern Ireland, 1947-1951. Land utilisation survey of Northern Ireland 1:63 360: sheets 1-10. Geographical Association of Northern Ireland, Queen's University, Belfast.

Grasty RL, Minty BRS. 1995. A Guide to the Technical Specifications for Airborne Gamma-ray Surveys. Record 1995/60. Australian Geological Survey Organisation: Canberra.

Hautaniemi H, Kurimo M, Multala J, Leväniemi H. Vironmäki J. 2005. The 'three in one' aerogeophysical concept of GTK in 2004. In Aerogeophysics in Finland 1972-2004: Methods, System Characteristics and Applications, Airo, ML (ed). Special Paper 39, Geological Survey of Finland: Espoo; 21-74.

IAEA 1991. Airborne Gamma Ray Spectrometer Surveying. Technical Report Series, No 323. International Atomic Energy Agency: Vienna.

IAEA 1993. Guidelines for radioelement mapping using gamma ray spectrometry data. IAEA-TECDOC-1363. International Atomic Energy Agency: Vienna

ICRU 1994. Gamma-ray Spectrometry in the Environment. Report No 53 the International Commission on Radiation Units and Measurements: Bethesda, USA. 
Izrael YA. 1993. Map of the Caesium-137 Radioactive Contamination of the European Part and Ural Region of Russia. 1993. 1:5000000 Russian State Cartographic Services: Moscow.

Jackson D, Jones SR, Fulker MJ, Coverdale NGM. 1987. Environmental monitoring in the vicinity of Sellafield following deposition of radioactivity from the Chernobyl accident. Journal of the Society for Radiological Protection 7: 75-87.

Jarvis NJ, Taylor A, Larsbo M, Etana A, Rosén K. 2010. Modelling the effects of bioturbation on the re-distribution of ${ }^{137} \mathrm{Cs}$ in an undisturbed grassland soil. European Journal of Soil Science 61: 24-34.

Jordan C, Higgins A. 2007. A generalised map of major soil types for Northern Ireland at a scale of 1:250,000. Agri-Food and Biosciences Institute, Belfast. Based on information In Soil and Environment: Northern Ireland, Cruickshank, JG (ed). 1997. Agricultural and Environmental Science Department, Queen's University, Belfast.

Kinnersley RP, Goddard AJH, Minski MJ, Shaw G. 1997. Interception of caesiumcontaminated rain by vegetation. Atmospheric Environment 31: 1137-1145.

Kirchner G, Baumgartner D. 1992. Migration rates of radionuclides deposited after the Chernobyl accident in various North German soils. Analyst 117: 475-479.

McAlister JJ, Cooney G, Higgins MJ 1997. Accumulation of uranium in granitic soils Overlying the Mourne Mountains, County Down, Northern Ireland. Microchemical Journal 56: 315-326.

McAulay IR, Moran D. 1989. Radiocaesium fallout in Ireland from the Chernobyl accident. Journal of Radiological Protection 9: 29-32.

Minty BRS, 1998. Multichannel models for the estimation of radon background in airborne gamm-ray spectrometry. Geophysics 63: 1986-1996. 
Nunes de Lima VS. 2005. IMAGE 2000 and $C L C_{2000}$ Products and Methods. European Commission Joint Research Centre: Ispra.

Palsson SE, Howard BJ, Wright SM. 2006. Prediction of spatial variation in global fallout of $137 \mathrm{Cs}$ using precipitation. Science of the Total Environment 367: 745756.

Patterson HD, Thompson R. 1971. Recovery of inter-block information when block sizes are unequal. Biometrika 58: 545-554.

Pitkin JA, Duval JS. 1980. Design parameters for aerial gamma-ray surveys. Geophysics 45: 1427-1439.

Quinn P, Beven K, Chevallier P, Planchon O. 1991. The prediction of hillslope paths for distributed hydrological modelling using digital terrain models. Hydrological Processes 5: 59-79.

Smith FB, Clark MJ. 1989. The transport and deposition of radioactive debris from the Chernobyl nuclear power plant accident. Meteorological Office Scientific Paper No 42. Her Majesty's Stationery Office: London.

Sweek L, Wauters J, Valcke E, Cremers A. 1990. The specific interception potential of soils for radiocaesium. In Transfer of Radionuclides in Natural and Seminatural Environments, Desmet G, Nassimbeni P, Belli M. (eds). Elsevier: London; 249258.

Tarboton DG. 1997. A new method for the determination of flow direction and upslope areas in grid digital elevation models. Water Resources Research 33: 309-319.

Tyler AN, 2007. In Situ and airborne gamma-ray spectrometry. In Analysis of Environmental Radionuclides, Povinec PP. (ed). Elsevier: London; 532pp.

Tyler AN, Heal KV. 2000. Predicting areas of ${ }^{137}$ Cs loss and accumulation in upland catchments. Water, Air and Soil Pollution 121: 271-288. 
Van Berghe I, Gulink H. 1987. Fallout ${ }^{137}$ Cs as a tracer for soil mobility in the landscape framework of the Belgian Loamy Region. Pedologie 37: 5-20.

Van der Perk M, Slávik O, Fulajtár, E. 2002. Assessment of spatial variation of cesium-137 in small catchments. Journal of Environmental Quality 31: 19301939.

Van Remortel RD, Hamilton ME, Hickey RJ. 2001. Estimating the LS factor for RUSLE through iterative slope length processing of digital elevation data within ArcInfo Grid. Cartography 30: 27-35.

Waegeneers N, Smolders E, Merckx R. 1999. A statistical approach for estimating radiocesium interception potential of soils. Journal of Environmental Quality 28: $1005-1011$.

Walling DE, Quine TA. 1991. Use of ${ }^{137}$ Cs measurements to investigate soil erosion on arable fields in the UK: potential applications and limitations Journal of Soil Science 42: 147-165.

Wright, SM, Howard BJ, Strand P, Nylén T, Sickel MAK. 1999. Prediction of 137Cs deposition from atmospheric nuclear weapons tests within the Arctic. Environmental Pollution 104: 131-143.

Wright SM, Howard DC, Barry J, Smith JT. 2002. Spatial variation of radiocaesium in Cumbria. Geographical and Environmental Modelling 6: 203-216.

Zapata F. 2002. Handbook for the Assessment of Soil Erosion and Sedimentation using Environmental Radionuclides. Kluwer Academic Publishers: Dordrecht. 


\section{List of Figures and Captions}

Figure 1. Map of rainfall which intercepted radioactivity in the Chernobyl plume across Northern Ireland, 2-4 May 1986 (after Smith and Clark, 1989; ${ }^{\circledR}$ Met Office).

Figure 2. Simple classification map of the dominant soil types across Northern Ireland. Source: Agri-Food and Biosciences Institute (AFBI), Belfast. For further details see Jordan and Higgins (2007).

Figure 3. The spatial distribution of the activity of ${ }^{137} \mathrm{Cs}\left(\mathrm{kBq} \mathrm{m}^{-2}\right)$ across Northern Ireland from the Tellus airborne geophysical survey of 2005-2006 overlain on a digital elevation model. Four upland areas are labelled: (A) the Tertiary basalt plateau, (B) the Mourne Mountains, (C) the plateau area to the west of Lough Erne, and (D) the Sperrin Mountains. Coordinates are in metres of the Irish National Grid.

Figure 4. Comparison of in-situ and airborne measurements of the activities of ${ }^{137} \mathrm{Cs}$ at 80 reference locations.

Figure 5. Auto-variograms of ${ }^{137} \mathrm{Cs}\left(\mathrm{kBq} \mathrm{m}^{-2}\right)$ for the areas receiving $15-20 \mathrm{~mm}$ of rainfall (see Figure 1) and the residuals of ${ }^{137} \mathrm{Cs}$ from regression models for altitude and soil type fitted to the original data. The symbols are estimates of the experimental semivariances, and the lines show the models fitted to them.

Figure 6. Auto-variograms of ${ }^{137} \mathrm{Cs}\left(\mathrm{kBq} \mathrm{m}^{-2}\right)$ for the rainfall classes in Figure 1 (after Smith and Clark, 1988). The symbols are estimates of the experimental and cross-variances, and the lines show the models fitted to them.

Figure 7. Auto- and cross-variograms for (a) K, (b) Cs and (c) Cs $\times$ K. The symbols are estimates of the experimental- and cross-variances, and the solid lines show the models fitted to them. The dashed lines in the autovariograms show the 
variance in the data. Solid lines show the hulls of perfect correlation in the cross-variograms.

Figure 8. Box-and-whisker plot of ${ }^{137} \mathrm{Cs}\left(\mathrm{kBq} \mathrm{m}^{-2}\right)$ activities for soil types across areas receiving between 15 and $20 \mathrm{~mm}$ of rainfall (see Figure 1). The dashed line shows the median of all the data; the circles are outliers. 
Table 1. Summary statistics for activities of ${ }^{137}$ Cs for sites from the airborne geophysical survey and for the separate rainfall classes mapped in Figure 1.

\begin{tabular}{lrrrrrr}
\hline Rainfall class (mm) & Count & Mean & Median & Variance & St. dev. & Skewness \\
\hline all sites & 1210555 & 2.03 & 2.00 & 0.96 & 0.98 & 0.23 \\
$<5$ & 66451 & 1.56 & 1.55 & 0.73 & 0.85 & 0.15 \\
$5-10$ & 484054 & 1.69 & 1.71 & 0.99 & 1.00 & 0.13 \\
$10-15$ & 357638 & 2.11 & 2.09 & 1.03 & 1.02 & 0.15 \\
$15-20$ & 152808 & 2.23 & 2.24 & 1.06 & 1.03 & -0.10 \\
$>20$ & 14170 & 2.20 & 2.21 & 0.95 & 0.98 & -0.14 \\
\hline \hline & & & & & & \\
\hline
\end{tabular}


Table 2. Values of parameters of exponential models fitted to experimental variograms of radiocaesium, ${ }^{137} \mathrm{Cs}$. The parameters are as follows: $c_{0}$ is the nugget variance, $c_{1}$ and $c_{2}$ are, respectively, in units of $\left(\mathrm{kBq} \mathrm{m}^{-2}\right)$ the sill variances of the short- and long-range components, and $a_{1}$ and $a_{2}$ are the corresponding distance parameters.

\begin{tabular}{|c|c|c|c|c|c|}
\hline \multirow[b]{2}{*}{ Rainfall/mm } & \multicolumn{3}{|c|}{ Variances } & \multicolumn{2}{|c|}{ Distance parameters } \\
\hline & $c_{0}$ & $c_{1}$ & $c_{2}$ & $a_{1} / \mathrm{km}$ & $a_{2} / \mathrm{km}$ \\
\hline$<5$ & 0.5781 & 0.1205 & 0.3366 & 2.63 & 45.3 \\
\hline $5-10$ & 0.5398 & 0.2930 & 0.1850 & 2.31 & 55.0 \\
\hline $10-15$ & 0.3790 & 0.3426 & 0.3812 & 0.26 & 10.9 \\
\hline $15-20$ & 0.5294 & 0.2211 & 0.4089 & 1.08 & 10.7 \\
\hline
\end{tabular}

Residuals for $15-20 \mathrm{~mm}$ rainfall

$\begin{array}{cccccc}\text { From altitude } & 0.5145 & 0.2315 & 0.3927 & 1.00 & 11.5 \\ \text { From soil type* } & 0.5261 & & 0.4775 & & 8.46 \\ & & & & & \\ \text { de and soil type } & 0.1994 & 0.4143 & 0.2653 & 0.21 & 3.16\end{array}$

* Single exponential model fitted. 
Table 3. Results from one-way analysis of variance of activities of ${ }^{137} \mathrm{Cs}(n=5000)$ for (a) soil type, and (b) land cover class.

\begin{tabular}{lcccc}
\hline & Degrees of freedom & Sum of squares & Mean square & $F$ ratio \\
\hline (a) & 39 & & & \\
Soil & 4948 & 762 & 19.5 & 23.4 \\
Residual & 4987 & 4123 & 0.833 & \\
Total & & 4885 & & \\
\hline (b) & & & & \\
Land cover & 26 & 785.5 & & \\
Residual & 4961 & & & \\
Total & 4987 & 40.2 & & \\
\hline \hline
\end{tabular}


Table 4. Results from REML unbalanced factorial analysis of ${ }^{137} \mathrm{Cs}$ for land cover and soil type and their interaction. Terms were added sequentially to the fixed model, first with land cover followed by soil type and then with soil type followed by land cover.

\begin{tabular}{lcccc}
\hline Fixed term & Wald statistic & Degrees of freedom & Approximate $F$ & $P$ \\
\hline Land cover & 997.0 & 26 & 38.3 & $<0.001$ \\
Soil type & 190.9 & 39 & 4.89 & $<0.001$ \\
\hline Soil type & 966.4 & 39 & 24.8 & $<0.001$ \\
Land cover & 220.4 & 26 & 8.48 & $<0.001$ \\
\hline Land cover $\times$ Soil type & 283.3 & 195 & 1.45 & $<0.001$ \\
\hline \hline
\end{tabular}

Total variance $0.9796\left(\mathrm{kBq} \mathrm{m}^{-2}\right) ; \quad$ residual variance $0.7880\left(\mathrm{kBq} \mathrm{m}^{-2}\right)$ 
Table 5. Nugget and sill variances in units of $\left(\mathrm{kBq} \mathrm{m}^{-2}\right)^{2}$ of linear model of coregionalization fitted to the variograms of radiocaesium, ${ }^{137} \mathrm{Cs}$, and potassium with distance parameter $0.393 \mathrm{~km}$.

\begin{tabular}{lcc}
\hline Elements & Nugget variance & $\begin{array}{c}\text { Sill variance of } \\
\text { correlated structure }\end{array}$ \\
\hline Potassium & 0.0026 & 0.5583 \\
Caesium $\times$ potassium & -0.0483 & 0.4307 \\
Caesium & 0.8926 & 0.7113 \\
\hline \hline
\end{tabular}


Figure 1:

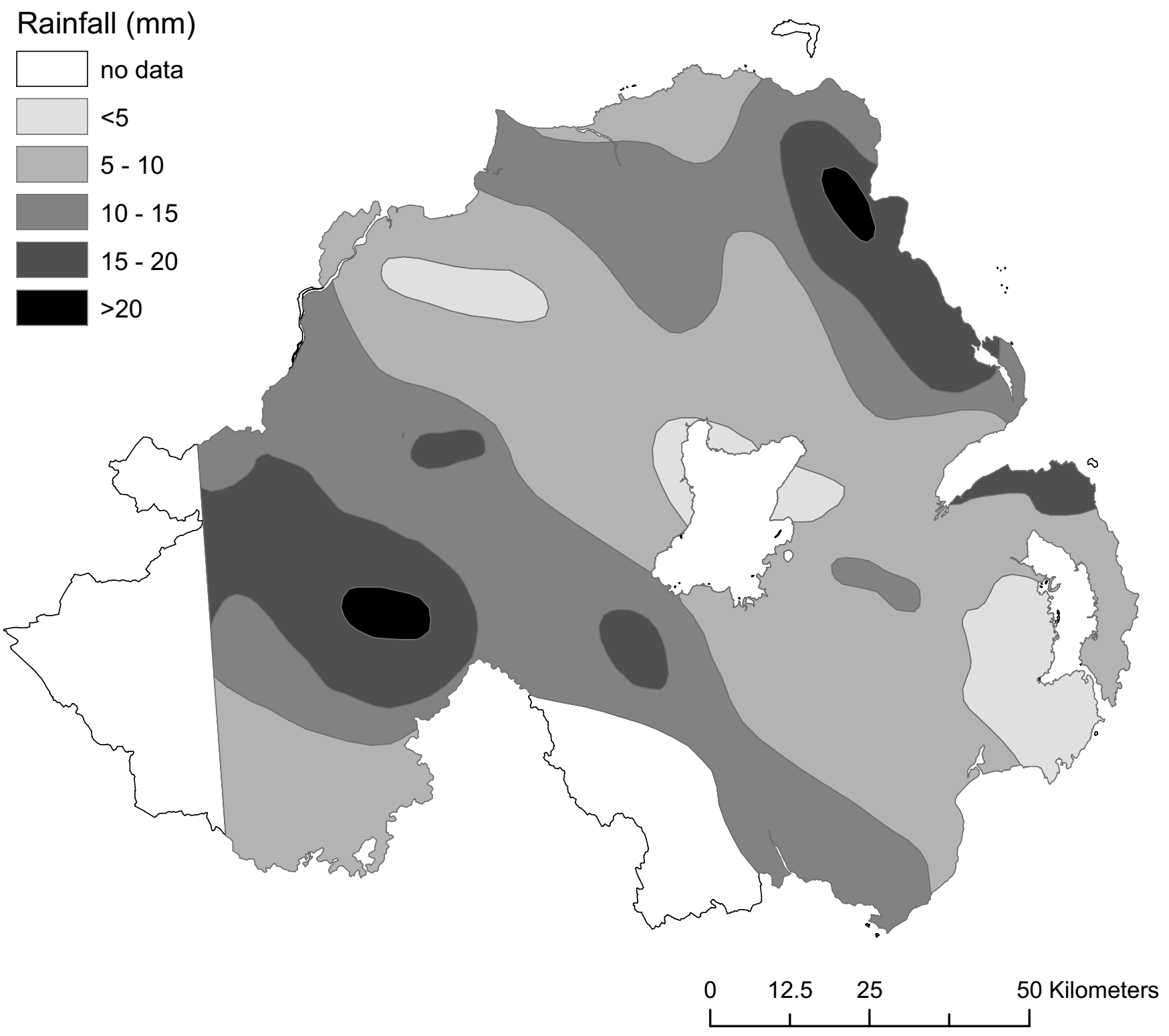




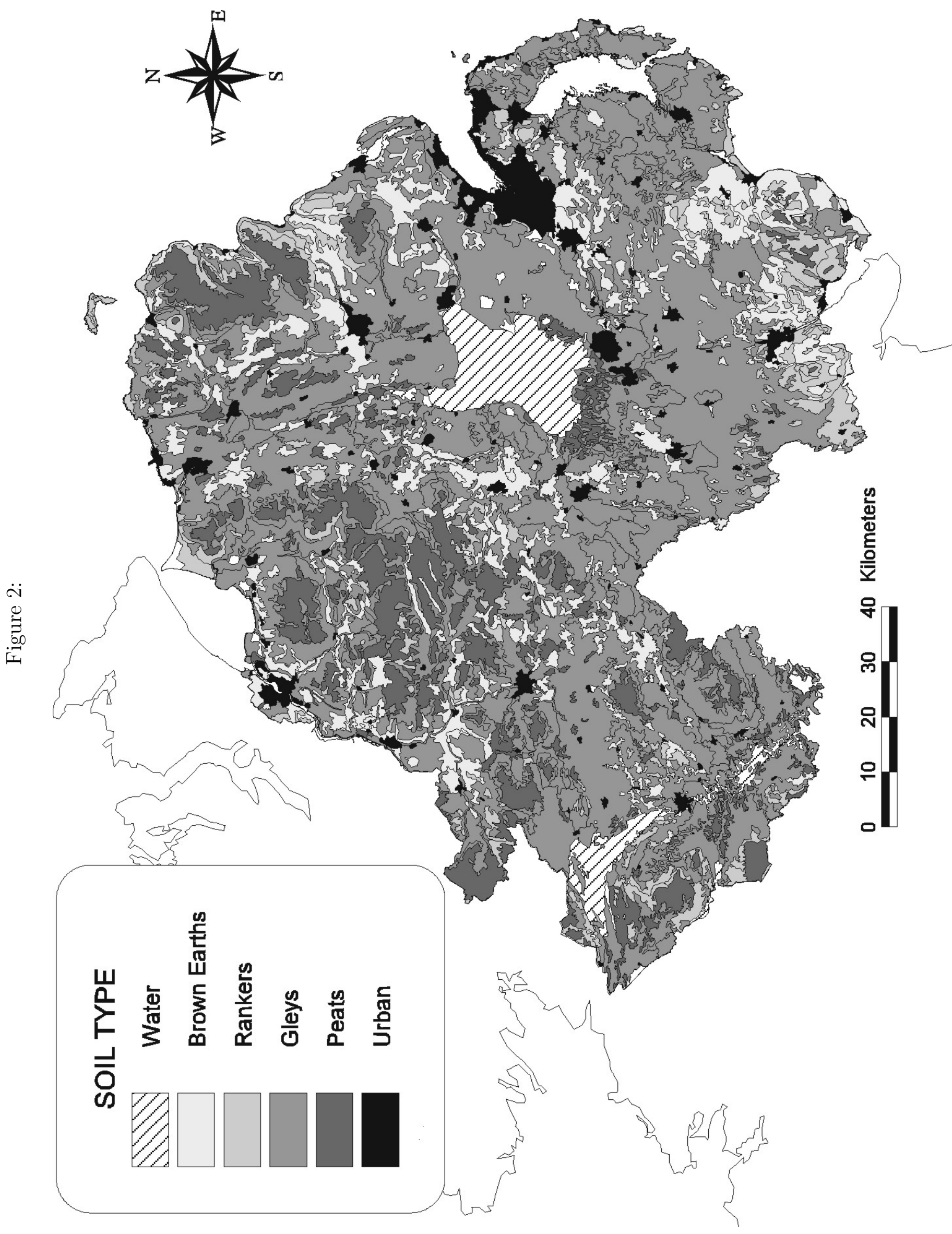




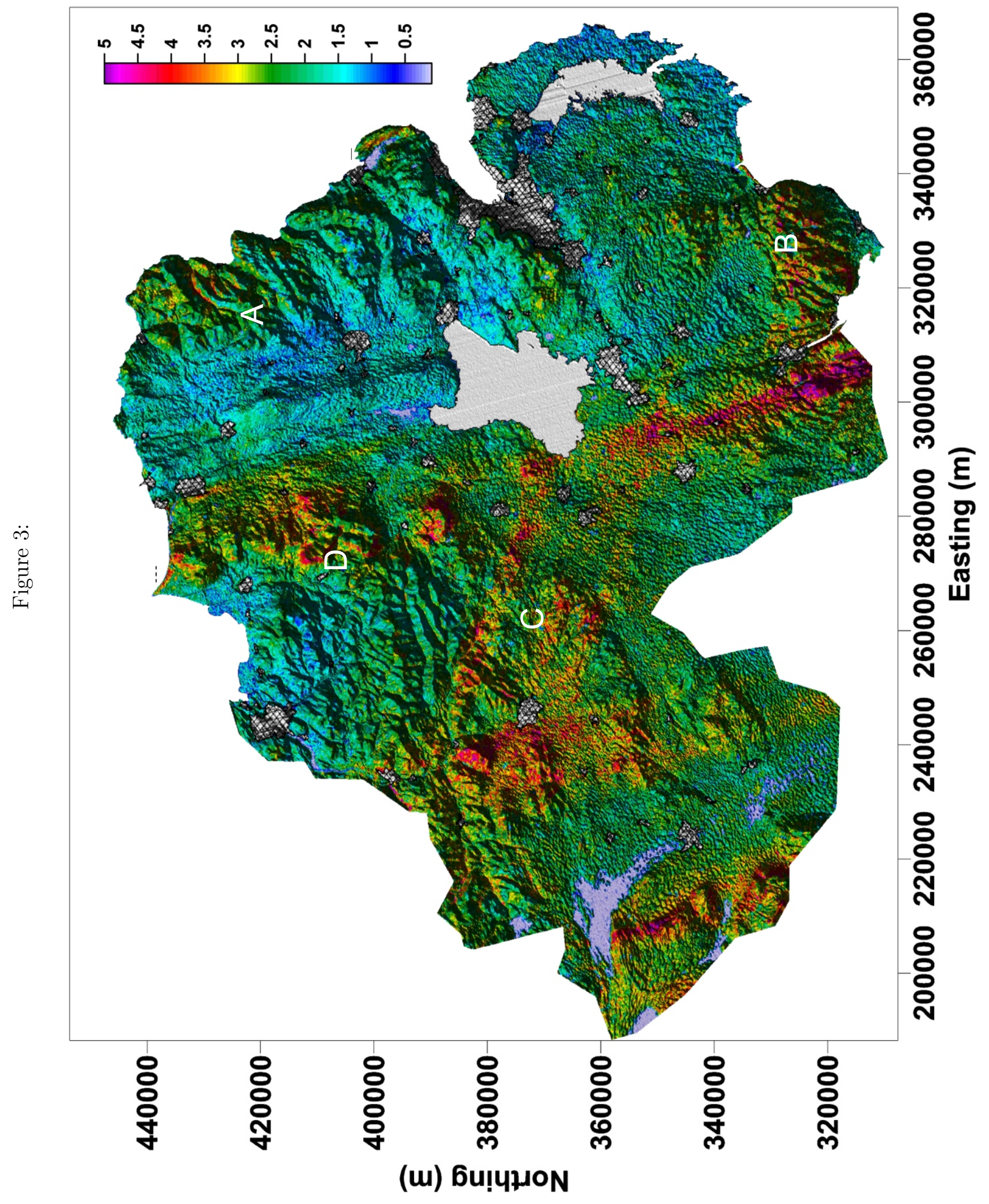


Figure 4:

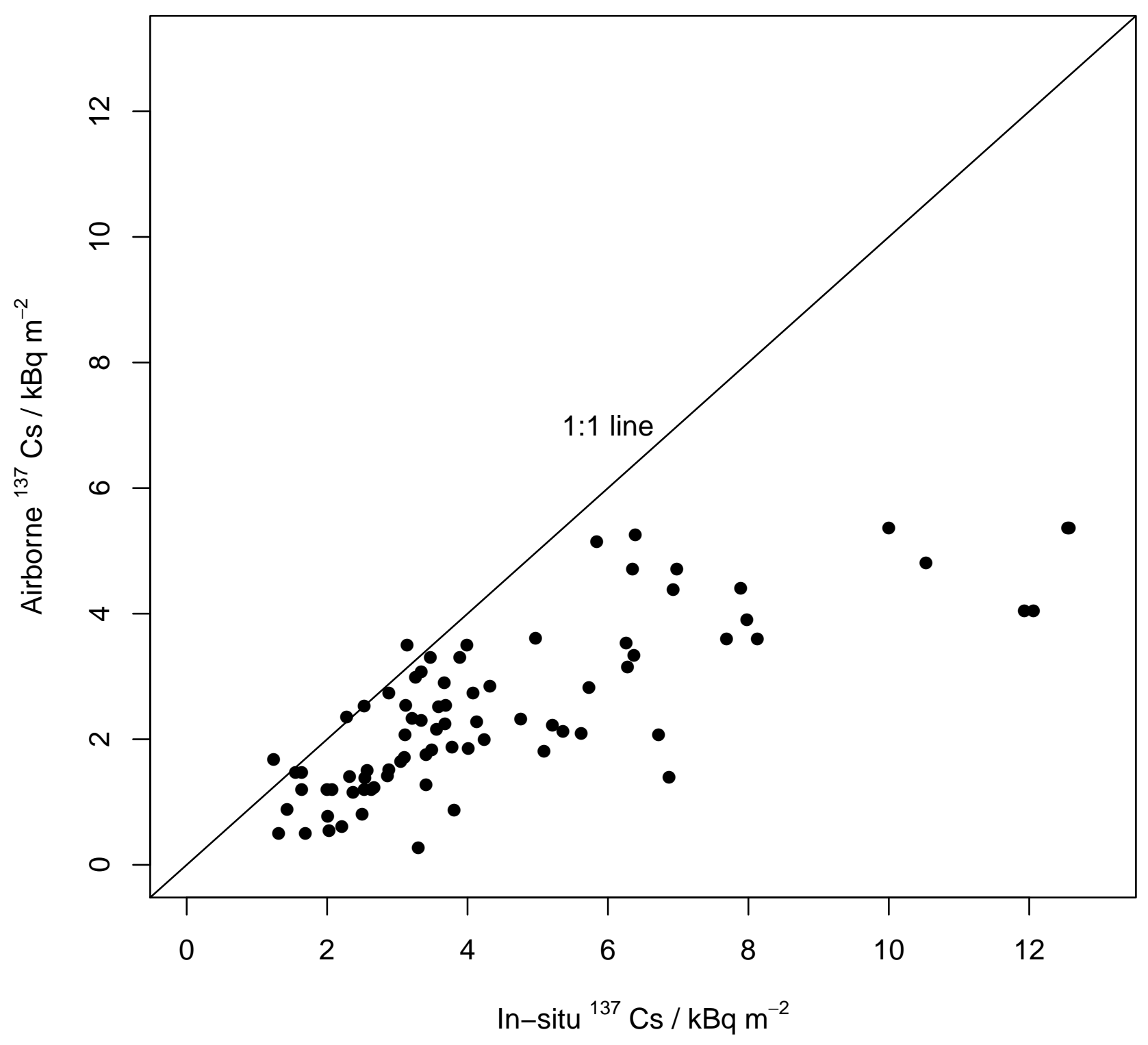


Figure 5:

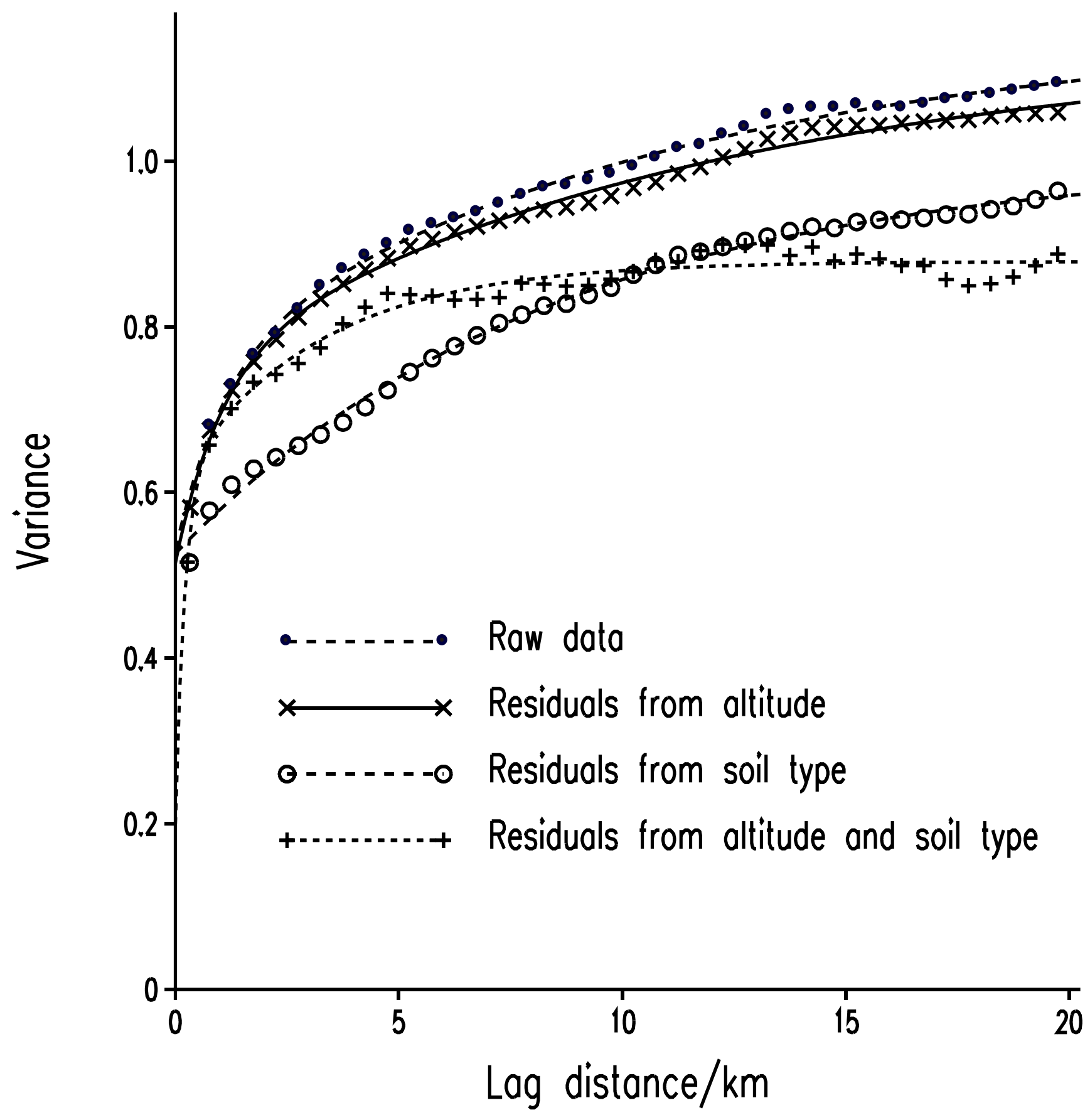


Figure 6:

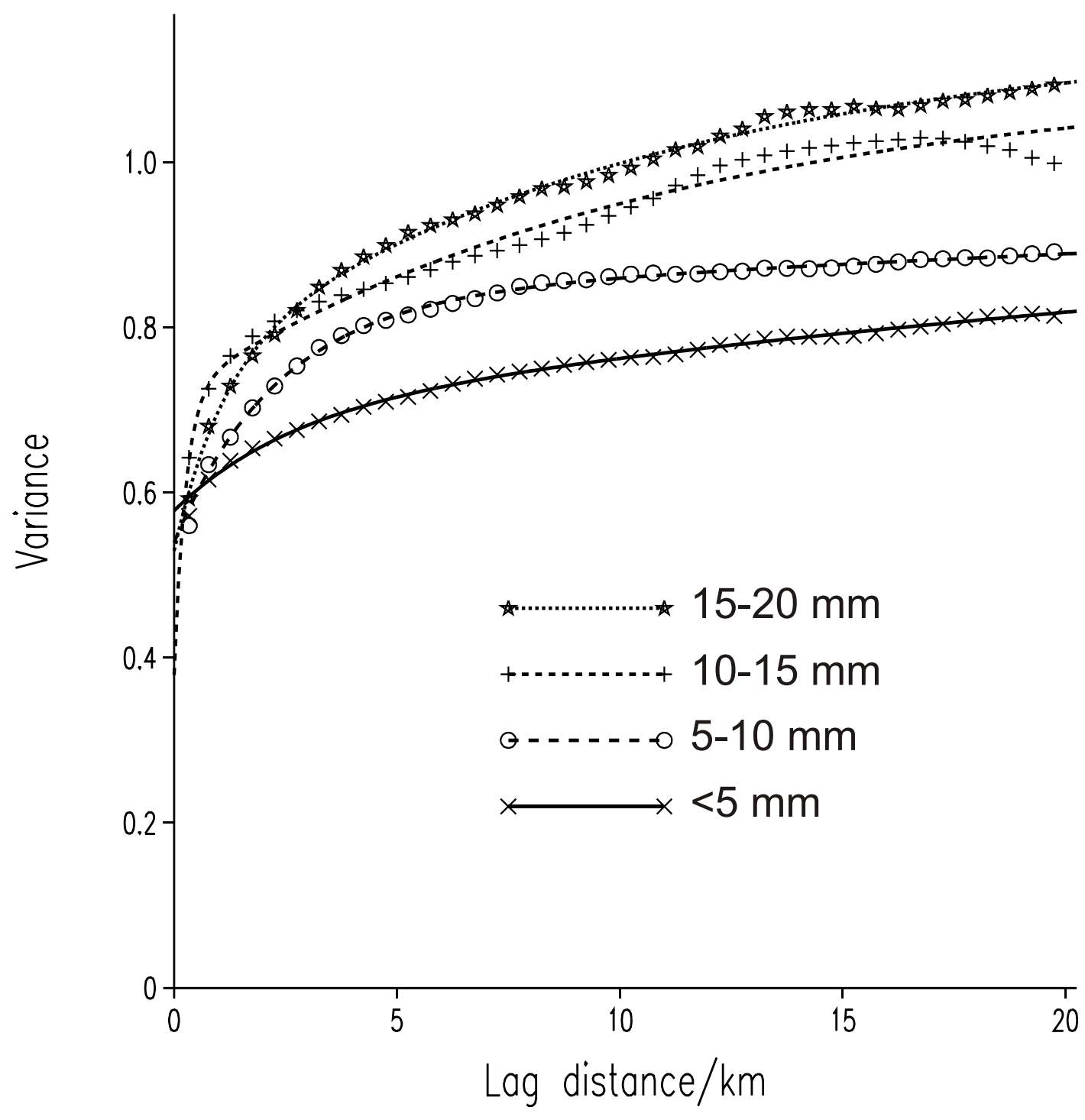


Figure 7:
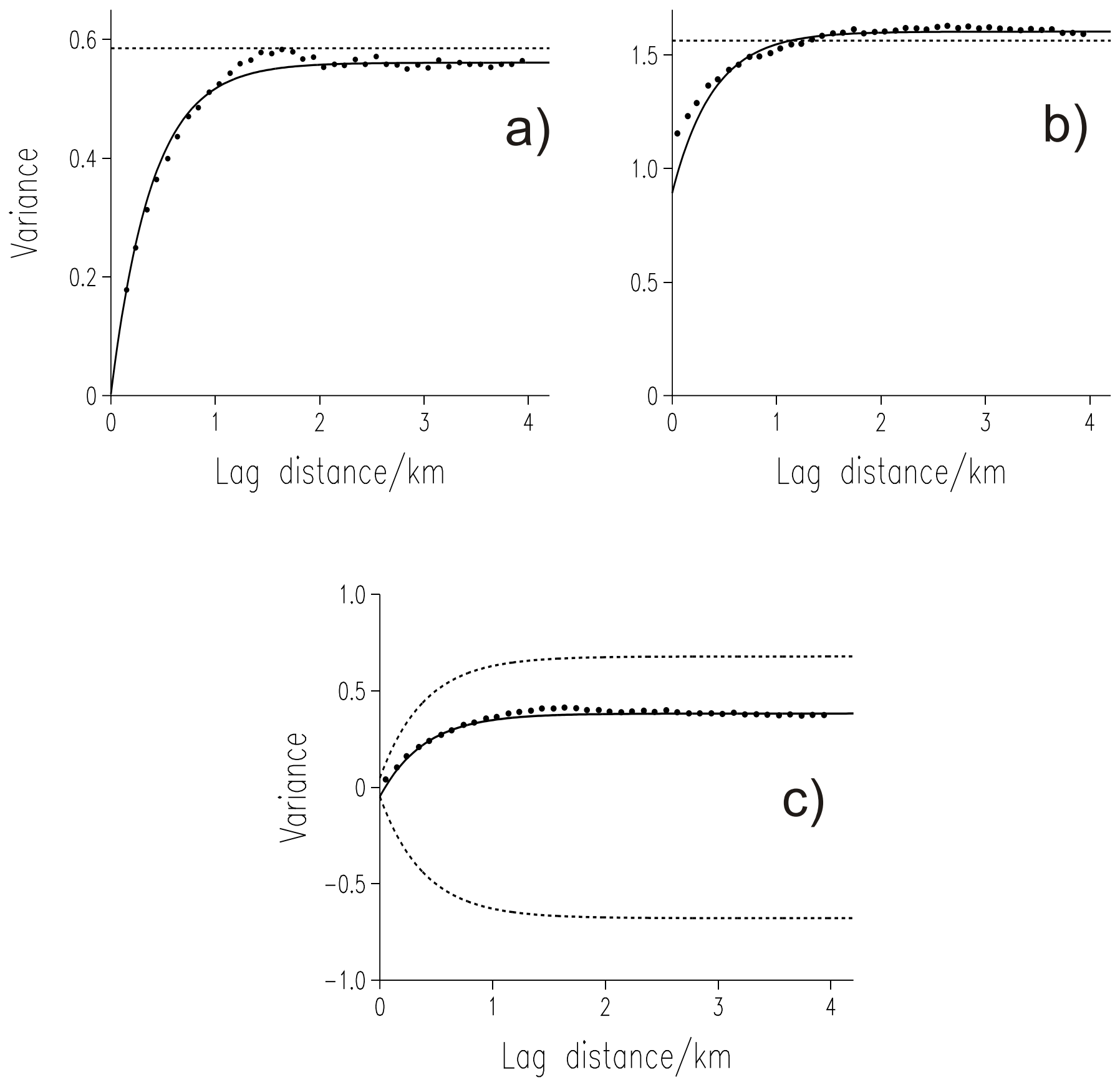
Figure 8:

${ }^{137} \mathrm{Cs}\left(\mathrm{kBq} \mathrm{m}^{-2}\right)$

All types of peat $>50 \mathrm{~cm}$

Surface Water Gley

Calcareous brown earth

Gleyic rankers

Brown Rankers

Brown Earth $>40 \mathrm{~cm}$ to $C$ Horizon

Humic ranker

Brown Podzolic(with Bs horizon)

Raw Skeletal

Stagno-Humic Gley

Pelosols

Ferritic ranker

Ground Water Gley

Peat podzols

Gleyed brown earth

Peaty ranker

Shallow brown podzol

Surface Water Humic Gley

Disturbed land

Organic/Mineral Alluvium

Shallow Brown Earths

Alluvium - mineral with var. textures

Podzol

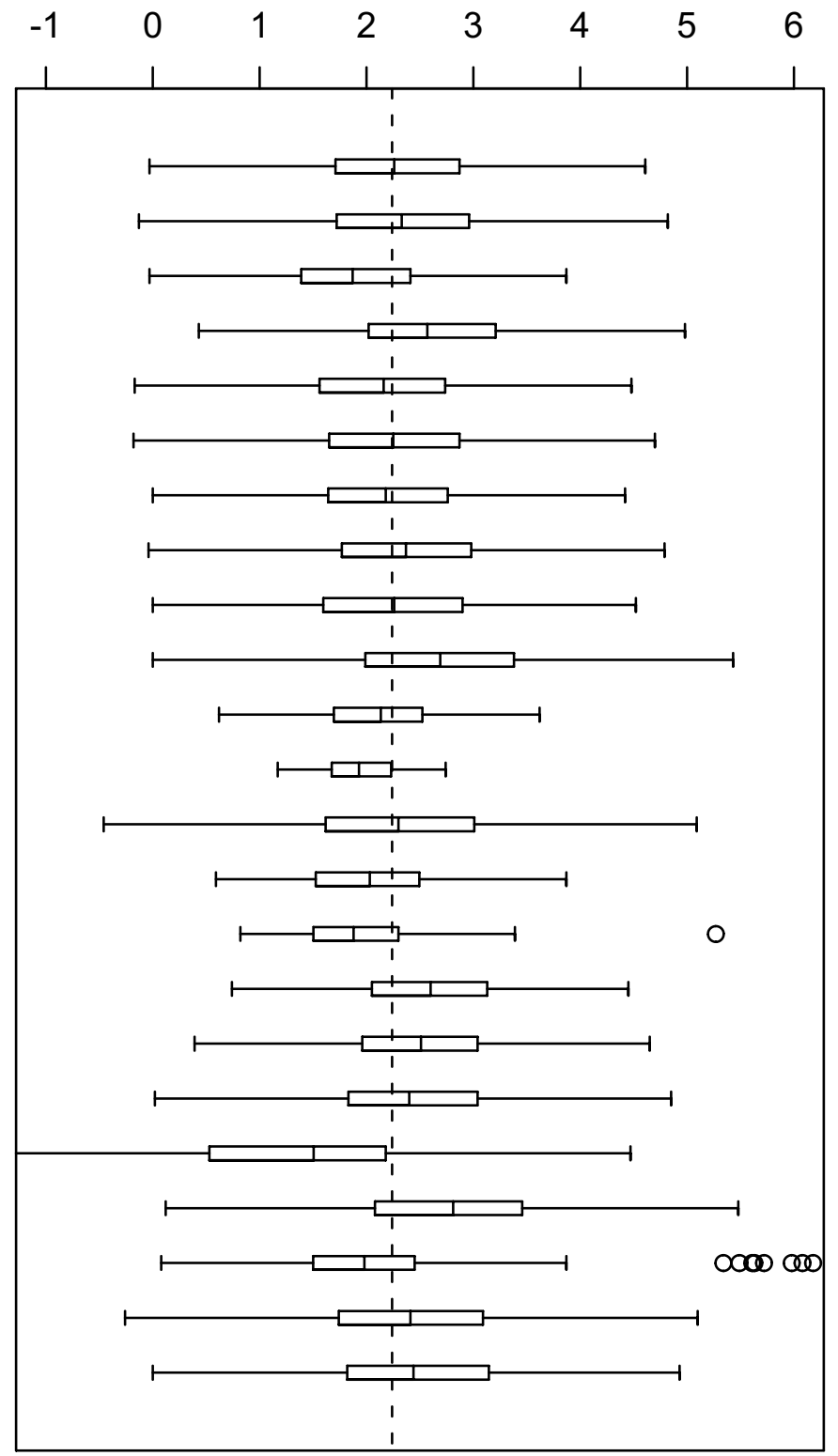

